\title{
One "misunderstood" health issue: demonstrating and communicating the safety of influenza a vaccination in pregnancy: a systematic review and meta- analysis
}

Qing Chun Lu ${ }^{1+}$, Tie Yun Zhang ${ }^{2+}$, Pravesh Kumar Bundhun ${ }^{3}$ and Cheng Chen ${ }^{4^{*}}$

\begin{abstract}
Background: The American College of Obstetricians and Gynecologists (ACOG) makes certain recommendations including the annual influenza vaccination of pregnant and pre-pregnant women during influenza (flu) season with an inactivated influenza vaccine as soon as it becomes available. The Centers for Disease Control and Prevention's (CDC) Advisory Committee on Immunization Practices in association with ACOG state that the vaccine is safe to be given any trimester during pregnancy. However, due to a lack of communication, the public is unaware of the effects of influenza A vaccination in pregnancy. Since this is a vital public health concern, we aimed to communicate with evidence, the safety of influenza A vaccination in pregnancy in order to improve the rate of influenza A vaccines in pregnant women.

Methods: This health communication issue was based on the impact of influenza vaccine on fetal outcomes. Therefore, a search was carried out through medical-based online databases including: Cochrane Central, EMBASE, Web of Science, MEDLINE, http://www.ClinicalTrials.gov, and Google scholar for relevant English-based publications. Adverse fetal outcomes were considered as the endpoints of this analysis. The most specific RevMan 5.3 (latest version) software was used to carry out this analysis. Risk ratios (RR) with 95\% confidence intervals (Cl) were involved in data and results representation and interpretation.
\end{abstract}

\footnotetext{
*Correspondence: 15062275812@163.com

${ }^{\dagger}$ Qing Chun Lu and Tie Yun Zhang contributed equally to this work and they are the first co-authors.

${ }^{4}$ Department of Broadcasting and Television, School of Journalism and

Information Communication, Huazhong University of Science and Technology, Wuhan 430000, People's Republic of China

Full list of author information is available at the end of the article
}

(C) The Author(s). 2021 Open Access This article is licensed under a Creative Commons Attribution 4.0 International License, which permits use, sharing, adaptation, distribution and reproduction in any medium or format, as long as you give appropriate credit to the original author(s) and the source, provide a link to the Creative Commons licence, and indicate if changes were made. The images or other third party material in this article are included in the article's Creative Commons licence, unless indicated otherwise in a credit line to the material. If material is not included in the article's Creative Commons licence and your intended use is not permitted by statutory regulation or exceeds the permitted use, you will need to obtain permission directly from the copyright holder. To view a copy of this licence, visit http://creativecommons.org/licenses/by/4.0/ The Creative Commons Public Domain Dedication waiver (http://creativecommons.org/publicdomain/zero/1.0/) applies to the data made available in this article, unless otherwise stated in a credit line to the data. 


\begin{abstract}
(Continued from previous page)
Results: A total number of 679, 992 pregnant women participated in this analysis. Based on this current analysis, premature/preterm birth ( $<37$ weeks) was significantly reduced in pregnant women who were vaccinated for influenza A (RR: $0.80,95 \%$ Cl: $0.69-0.92 ; P=0.002)$ as compared to those women who were not vaccinated. Similarly, influenza A vaccination decreased the risk for very preterm birth ( $<32$ weeks) (RR: 0.70, 95\% Cl: 0.58-0.84; $P=$ 0.0001). The risks for infants with low birth weight (RR: $0.71,95 \% \mathrm{Cl}: 0.49-1.04 ; P=0.08$ ), very low birth weight (RR: $0.69,95 \%$ Cl: $0.23-2.11 ; P=0.52$ ) and infants small for gestational age (RR: $0.93,95 \%$ Cl: $0.83-1.05 ; P=0.26$ ) were not increased with the vaccine. Influenza A vaccination was not associated with increased risks of stillbirth (RR: 0.63 , 95\% Cl: $0.38-1.03 ; P=0.07$ ), birth defects (RR: $0.67,95 \% \mathrm{Cl}: 0.26-1.72 ; P=0.41$ ), admission to neonatal intensive care unit or Apgar score $<7$ in 5 min.

Conclusion: Influenza vaccine is completely safe in pregnancy. It significantly lowers premature birth and is not associated with any serious adverse neonatal outcome. Hence, this important piece of information should be communicated and conveyed to all pregnant women, for a safer and healthier pregnancy. At last, this public health issue should further be addressed to the population through media and other communication means in order to improve the rate of influenza A vaccines in pregnant women for a healthier and more productive population.
\end{abstract}

Keywords: Health communication, Communication scholars, Influenza vaccine, Fetal outcomes, Pregnancy, Public health, Risk ratio, Centre of disease control and prevention

\section{Background}

For a long time, "health" and "communication" have always been playing an important role in human production and life. As a concept, "health communication" was formally put forward in the 1970s. Similar to other concepts in Humanities and Social Sciences, people also have different opinions on health communication, forming multi-dimensional interpretations. However, the most classic definition is the view of Rogers, a pioneer in communication, "Health communication is any type of human communication whose content is concerned with health" [1]. Simply speaking, health communication is a kind of behavior that produces and delivers information related to human health. For example, a research work based on a specific health-related topic demonstrating and explaining certain guidelines and preventive measures could be shared among several groups of people who are concerned with the issue. In this process, communication plays the role of a "controller".

Health communication has been introduced into public health and education for heath by American scholars since 1960s, enriching and developing the theory and methods of health education. In general, the Stanford Heart Disease Prevention Program (SHDPP) launched in the United States in 1971, is regarded as the real beginning of health communication research.

The ultimate purpose of health communication has been to make people form a change from cognition to action; to promote public and individual's physical/mental health; to accomplish a harmonious operation in our whole society [2]. In other words, "health communication" has set up its mission to persuade the public of adopting health behaviors and preventive measures proven to be safe and effective. As such, Influenza A vaccination is an essential health concern during pregnancy.

Vaccination during pregnancy has often been a controversy among the current general population. People are not well informed, and prefer to avoid any kind of vaccination during pregnancy because they are unsure or unaware of its consequences or effects on the fetus [3]. Similarly, people are not aware of the importance of inactivated influenza vaccine during pregnancy [4]. Due to a lack of communication, the public is unaware of the benefit and they have a belief that, similar to other vaccines, influenza A vaccine is also contraindicated during pregnancy $[5,6]$.

In contrast, influenza vaccination is actually vital during pregnancy because influenza can result in severe health conditions including progression to pneumonia during antepartum and postpartum periods [7]. This might be associated with adverse perinatal and neonatal outcomes [8]. Hence, vaccination against influenza A during pregnancy might be protective.

The American College of Obstetricians and Gynecologists (ACOG) makes certain recommendations including the annual influenza vaccination of pregnant and prepregnant women during influenza (flu) season with an inactivated influenza vaccine as soon as it becomes available. The Centers for Disease Control and Prevention's (CDC) Advisory Committee on Immunization Practices in association with ACOG state that the vaccine is safe to be given any trimester during pregnancy [9]. They also mention that maternal influenza immunization is an important constituent of maternal prenatal care as well as for the newborn. Medical Health Officers based in the department of Obstetrics and Gynecology, as well as other health care assistants are advised to counsel 
pregnant women about the safety and beneficial effects of influenza vaccination and passive immunity to their fetus.

Following the influenza A (H1N1) outbreak in the year 2009 , even though influenza vaccine was first recommended to all pregnant women irrespective of gestational age in the United Kingdom in November 2010 [10], hesitancy was observed among this specific category of patients. There was a delay or a complete absence of acceptance of the vaccine despite its availability in vaccination services as stated by The Strategic Advisory Group of Experts on Immunization (SAGE) Working Group [11] and it was believed that this hesitancy was due to a lack of communications concerning the safety of influenza A vaccine and other challenging concerns during pregnancy rendering a total of only $45 \%$ of pregnant women based in the United Kingdom to take this influenza A vaccination [12].

Since this is a vital public health concern, we therefore aimed to demonstrate and communicate with evidence, the safety of influenza A vaccination in pregnancy in order to improve the rate of influenza A vaccines in pregnant women.

\section{Methods}

\section{Search databases and search strategies}

This health communication issue was based on the impact of influenza vaccine on fetal outcomes. Therefore, a search was carried out through medical-based online databases: Cochrane Central, EMBASE, Web of Science, MEDLINE, http://www.ClinicalTrials.gov, and Google scholar for English-based publications.

Searched indices which were used were restricted to: "pregnancy and influenza vaccine"; "pregnancy and influenza"; "pregnancy and H1N1"; "pregnancy and vaccination"; "pregnancy, influenza and fetal outcomes"; "influenza vaccine and pregnancy outcomes"; "influenza and fetal outcomes"; "influenza A vaccine and pregnancy outcomes"; "H1N1 and pregnancy outcomes"; "influenza vaccination and pregnancy abnormalities"; "influenza A vaccination and pregnancy abnormalities".

\section{Inclusion and exclusion criteria}

Criteria for inclusion were based on studies which:

(a) Were randomized trials and observational studies (cohort, cross-sectional, retrospective, prospective studies);

(b) Compared pregnant women who were vaccinated versus those who were not vaccinated for influenza A (H1N1) and reported fetal outcomes as their clinical endpoints;

(c) Involved dichotomous data which could be used in this analysis; that is, data which used binary 'success' or 'failure' categories to describe the status of subjects.

Criteria for exclusion were based on studies which:

(a) Were systematic reviews, meta-analyses or literature reviews;

(b) Were case studies;

(c) Did not show the comparison of vaccinated versus unvaccinated pregnant women for influenza $\mathrm{A}$ (H1N1);

(d) Did not report fetal outcomes;

(e) Involved data which were irrelevant to this analysis;

(f) Were duplicated studies; that is, studies that repeated themselves in different search databases, and different studies that involved the same trial or observational cohort.

\section{Data extraction and quality assessment}

Data were independently extracted from the original studies by three reviewers. Data which were extracted involved the surnames of the first author, the publication year of the original articles, the maternal and fetal outcomes, the type of study, the total number of pregnant women who were vaccinated versus those who were not vaccinated, the percentage of women who suffered from gestational diabetes mellitus, high blood pressure, with multiple pregnancies and those on folic acid supplementation, the type of influenza vaccine, the number of events in each category and the methodological quality of each study.

The methodological quality of the observational studies (cross sectional and cohort studies) were assessed based on the criteria of the Newcastle Ottawa Scale (NOS) [13] whereas the methodological quality of the randomized trials were assessed by the criteria suggested by the Cochrane Collaboration [14]. Grades were allotted (Grade $\mathrm{A}=$ low risk of bias, Grade $\mathrm{B}=$ moderate risk of bias, Grade $\mathrm{C}=$ high risk of bias).

Any disagreement was discussed and resolved by the corresponding author (Cheng Chen).

\section{Outcomes}

Table 1 listed the fetal outcomes reported in the original studies.

The fetal endpoints which were assessed in this metaanalysis were limited to the following:

(a) Preterm birth $(<37$ weeks);

(b) Very preterm birth $(<32$ weeks);

(c) Low birth weight $(<2500 \mathrm{~g})$;

(d) Very low birth weight $(<1500 \mathrm{~g})$;

(e) Small for gestational age;

(f) Stillbirth; 
Table 1 Outcomes reported and follow-up time period

\begin{tabular}{|c|c|}
\hline Studies & Fetal outcomes \\
\hline Baum2015 [15] & Stillbirth, early neonatal death, preterm birth, very preterm, low birth weight, fetal growth restriction, full term, live birth \\
\hline Beau2014 [16] & Small for gestational age, neonatal pathology, preterm birth, pregnancy loss \\
\hline $\begin{array}{l}\text { Chambers2013 } \\
{[17]}\end{array}$ & Live birth, stillbirth, termination, congenital defects \\
\hline $\begin{array}{l}\text { Chambers } 2016 \\
{[18]}\end{array}$ & Major birth defects, small for gestation, spontaneous abortion, stillbirth, live birth, termination, preterm birth \\
\hline Cleary2014 [19] & $\begin{array}{l}\text { Small for gestation, preterm, spontaneous birth }<37 \text { weeks, admitted to neonatal unit, perinatal death, congenital anomaly, } \\
\text { Apgar score }<3 \text { at } 1 \text { min, Apgar score }<7 \text { at } 5 \text { min }\end{array}$ \\
\hline Fabiani2015 [20] & $\begin{array}{l}\text { Stillbirth, preterm birth }<37 \text { weeks, very preterm birth }<32 \text { weeks, low birth weight }<2500 \mathrm{~g} \text {, very low birth weight }<1500 \mathrm{~g} \text {, } \\
\text { low } 5 \text { min Apgar score }<7 \text {, congenital malformation }\end{array}$ \\
\hline Fell2012 [21] & Preterm birth $<37$ weeks, very preterm birth $<32$ weeks, small for gestation, 5 min Apgar score $<7$, fetal death \\
\hline Kallen2012 [22] & $\begin{array}{l}\text { Stillbirth, preterm birth, low birth weight, small for gestation, congenital malformation, cardiac malformation, VSD/ASD, } \\
\text { hypospadias, orofacial clefts, eye malformations }\end{array}$ \\
\hline Legge2014 [23] & Preterm birth < 37 weeks, low birth weight, small for gestational age \\
\hline Lin2012 [24] & $\begin{array}{l}\text { Preterm delivery, low birth weight, ASD, stillbirth, hyperbilirubinemia neonatal, contact dermatitis, upper respiratory tract } \\
\text { infection, respiratory distress }\end{array}$ \\
\hline Maas2015 [25] & Small for gestation, preterm $<37$ weeks \\
\hline Olsen2016 [26] & Small for gestational age, preterm \\
\hline $\begin{array}{l}\text { Pasternak2012 } \\
{[27]}\end{array}$ & Major birth defects, preterm birth, low birth weight, small for gestational age \\
\hline $\begin{array}{l}\text { Richards2013 } \\
{[28]}\end{array}$ & Preterm birth (27-36 weeks), low birth weight, small for gestational age \\
\hline $\begin{array}{l}\text { Rubinstein2013 } \\
{[29]}\end{array}$ & $\begin{array}{l}\text { Preterm birth }<37 \text { weeks, low birth weight, very low birth weight, fetal mortality, Apgar score }<7 \text { in } 5 \text { min, admission to neonatal } \\
\text { ICU, fetal malformation }\end{array}$ \\
\hline $\begin{array}{l}\text { Sheffield2012 } \\
\text { [30] }\end{array}$ & Preterm < 37 weeks, major malformation, stillborn, neonatal ICU, neonatal death, neonatal pneumonia \\
\hline $\begin{array}{l}\text { Steinhoff2012 } \\
\text { [31] }\end{array}$ & Small for gestational age, low birth weight, preterm $<37$ weeks \\
\hline $\begin{array}{l}\text { Steinhoff2017 } \\
{[32]}\end{array}$ & Preterm $<37$ weeks, small for gestation \\
\hline Zerbo2017 [33] & $\begin{array}{l}\text { Small for gestational age, preterm birth, low birth weight, admission to neonatal ICU, Apgar score }<7 \text { within } 1 \text { and } 5 \text { min } \\
\text { respectively }\end{array}$ \\
\hline
\end{tabular}

Abbreviations: ICU Intensive care unit, VSD ventricular septal defects, ASD Atrial septal defect

(g) Major birth defects;

(h) Admission to neonatal intensive care units (NICU);

(i) Apgar score $<7$ in $5 \mathrm{~min}$.

\section{Statistical analysis}

The most specific RevMan 5.3 (latest version) software was used to carry out this analysis. Risk ratios (RR) with 95\% confidence intervals (CI) were involved in data and results representation and interpretation.

A subgroup analysis of the outcomes with a $P$ value less or equal to 0.05 was considered statistically significant for this study. Any P value above 0.05 was not statistically significant.

Heterogeneity in meta-analysis, which is also referred to as the variation in study outcomes between studies, was represented by the $\mathrm{I}^{2}$ statistic test which described the percentage of variation across the studies that was due to heterogeneity rather than chance. The larger the percentage of $\mathrm{I}^{2}$, the higher the heterogeneity.

A random effect statistical model was used for this analysis.

Sensitivity analysis [34] was also carried out by a leave one out analysis whereby one study was excluded at a time and a new analysis was carried out each time to observe if the results were influenced by any of the studies.

Publication bias was visually observed through plotted funnels.

\section{Ethical approval}

Ethical or board review approval was not required for this systematic review and meta-analysis. 


\section{Results}

\section{Search outcomes}

Following a thorough search from the online databases (PRISMA Guideline) [35], a total number of 963 publications were retrieved. Based on an initial assessment of the titles and abstracts, 798 publications were eliminated due to irrelevance.

One hundred and sixty five (165) full texts articles were then assessed based upon the inclusion and exclusion criteria.

Elimination of full texts articles were based on the following aspects:

(a) They were systematic reviews, meta-analyses and literature reviews (17);

(b) They were case studies or letters of correspondence (8);

(c) They reported only maternal outcomes but did not report fetal outcomes (17);

(d) They did not show comparison of vaccinated versus unvaccinated women (19);

(e) They consisted of irrelevant data (4);

(f) They were duplicated/repeated studies and data (82).

Finally, 18 studies [15-33] were selected for this analysis as shown in Fig. 1.

\section{General and baseline features}

A total number of 679, 992 pregnant women participated in this analysis. One hundred and eighty one thousand four hundred and seventy nine $(181,479)$ pregnant women who were vaccinated were compared with 498, 513 pregnant women who were not vaccinated for influenza A.

Table 2 lists the total number of participants which were extracted from each group. Two studies were randomized trials, 2 studies were cross sectional studies whereas the remaining 14 studies were cohort studies. The bias risk grade for each study was also listed in Table 2.

As listed in Table 3, the average percentage of pregnant women who had gestational diabetes (GDM) ranged between 1.06 and $16.2 \%$, those with hypertension ranged from 0.42 to $51.9 \%$, those with multiple pregnancies ranged from 1.00 to $5.80 \%$.

\section{Main results}

Based on this analysis, premature/preterm birth $(<37$ weeks) was significantly reduced in pregnant women who were vaccinated for influenza A (RR: 0.80, 95\% CI: $0.69-0.92 ; P=0.002)$ as compared to those women who were not vaccinated as shown in Fig. 2. Similarly,

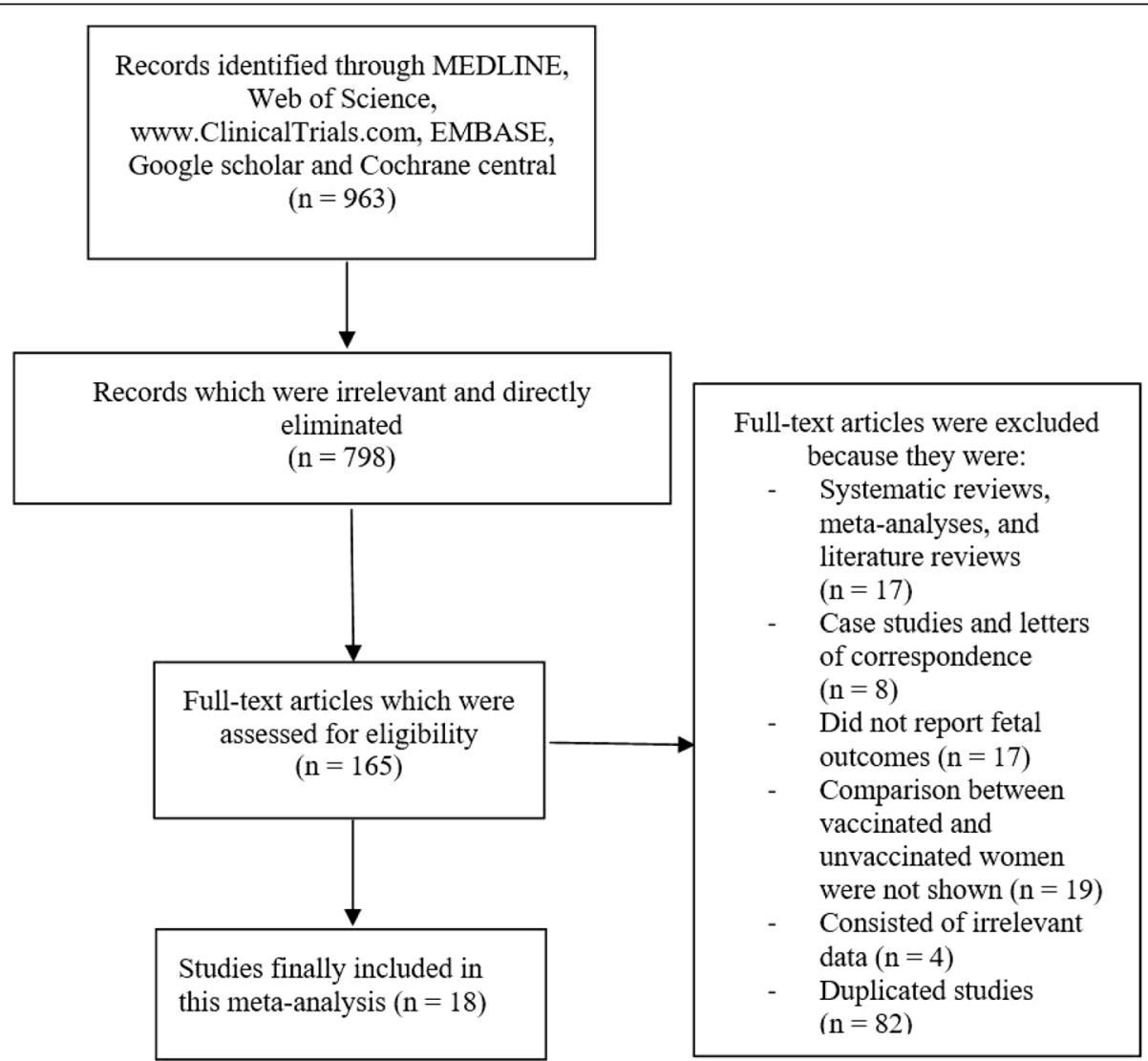

Fig. 1 Flow diagram representing the study selection 
Table 2 General properties of the studies

\begin{tabular}{|c|c|c|c|c|}
\hline Studies & No of women vaccinated (n) & No of women unvaccinated (n) & Type of study & Bias risk grade \\
\hline Baum2015 [15] & 34,241 & 9363 & Cohort study & B \\
\hline Beau2014 [16] & 1645 & 3290 & Cohort study & B \\
\hline Chambers2013 [17] & 841 & 191 & Cohort study & B \\
\hline Chambers 2016 [18] & 1263 & 467 & Cohort study & B \\
\hline Cleary2014 [19] & 2996 & 3898 & Cohort study & B \\
\hline Fabiani2015 [20] & 2003 & 98,329 & Cohort study & B \\
\hline Fell2012 [21] & 23,340 & 32,230 & Cohort study & B \\
\hline Kallen2012 [22] & 18,612 & 83,298 & Cohort study & B \\
\hline Legge2014 [23] & 1958 & 10,265 & Cohort study & B \\
\hline Lin2012 [24] & 198 & 198 & Cohort study & B \\
\hline Maas2015 [25] & 1357 & 669 & Cross sectional linkage study & B \\
\hline Olsen2016 [26] & 2172 & 2931 & Cohort study & B \\
\hline Pasternak2012 [27] & $345+6644$ & $22,917+46,443$ & Cohort study & B \\
\hline Richards2013 [28] & 1125 & 1545 & Cohort study & B \\
\hline Rubinstein2013 [29] & 7293 & 23,195 & Cross sectional study & B \\
\hline Sheffield2012 [30] & 8690 & 76,153 & Cohort study & B \\
\hline Steinhoff2012 [31] & 161 & 166 & Randomized trial & B \\
\hline Steinhoff2017 [32] & 1847 & 1846 & Randomized trial & B \\
\hline Zerbo2017 [33] & 64,748 & 81,119 & Cohort study & B \\
\hline Total no of participants (n) & 181,479 & 498,513 & & \\
\hline
\end{tabular}

Table 3 Baseline features reported by the participants

\begin{tabular}{lllll}
\hline Studies & $\begin{array}{l}\text { GDM (\%) } \\
\text { Vac/UV }\end{array}$ & $\begin{array}{l}\text { HBP (\%) } \\
\text { Vac/UV }\end{array}$ & $\begin{array}{l}\text { MP (\%) } \\
\text { Vac/UV }\end{array}$ & $\begin{array}{l}\text { FA suppl (\%) } \\
\text { Vac/UV }\end{array}$ \\
\hline Baum2015 [15] & & & & \\
Beau2014 [16] & $3.10 / 3.80$ & $0.90 / 1.20$ & $2.10 / 2.50$ & $27.4 / 18.5$ \\
Chambers2013 [17] & & $8.90 / 3.90$ & & $69.0 / 72.3$ \\
Chambers 2016[18] & & $8.10 / 5.50$ & $72.1 / 63.8$ \\
Cleary2014 [19] & - & - & - & - \\
Fabiani2015 [20] & - & - & $2.00 / 1.30$ & - \\
Fell2012 [21] & & $48.1 / 51.9$ & - & - \\
Kallen2012 [22] & $1.06 / 1.84$ & $0.42 / 0.74$ & - & - \\
Legge2014 [23] & $4.80 / 4.98$ & $1.02 / 1.11$ & - & - \\
Lin2012 [24] & - & - & - & - \\
Maas2015 [25] & - & - & - & - \\
Olsen2016 [26] & - & - & - & - \\
Pasternak2012 [27] & - & - & - & - \\
Richards2013 [28] & $16.2 / 15.6$ & $14.4 / 14.9$ & $5.30 / 5.80$ & - \\
Rubinstein2013 [29] & - & $4.10 / 3.60$ & - & - \\
Sheffield2012 [30] & $12.0 / 6.00$ & $9.00 / 9.00$ & $2.00 / 1.00$ & - \\
Steinhoff2012 [31] & - & - & - & - \\
Steinhoff2017 [32] & - & - & - & - \\
Zerbo2017 [33] & - & $2.10 / 1.87$ & - & - \\
\hline AbbreVafons 6DM Gesta & & - & - \\
\hline
\end{tabular}

Abbreviations: GDM Gestational diabetes, HBP High blood pressure, MP Multiple pregnancy, FA supp/ Folic acid supplement, Vac Vaccination, UV Unvaccinated influenza A vaccination also decreased the risk for very preterm birth (<32 weeks) (RR: 0.70, 95\% CI: 0.58-0.84; $P=0.0001)$ as shown in Fig. 2.

The risks for infants with low birth weight (RR: 0.71, 95\% CI: $0.49-1.04 ; P=0.08)$, very low birth weight (RR: 0.69, 95\% CI: $0.23-2.11 ; P=0.52)$ and infants small for gestational age (RR: $0.93,95 \% \mathrm{CI}: 0.83-1.05 ; P=0.26$ ) were not increased in the vaccination group as shown in Fig. 3.

Influenza A vaccination was not associated with increased risks of stillbirth (RR: 0.63, 95\% CI: 0.38-1.03; $P=0.07$ ), birth defects (RR: 0.67, 95\% CI: 0.26-1.72; $P=$ 0.41 ), admission to the neonatal intensive care unit (RR: 0.94, 95\% CI: 0.87-1.02; $P=0.13$ ) or an Apgar score $<7$ in 5 min (RR: $0.89,95 \% \mathrm{CI}: 0.78-1.02 ; P=0.09$ ) as shown in Fig. 4.

When the two randomized trials were excluded, and an analysis was carried out only with the observational cohorts, preterm birth was still significantly lower among women who were vaccinated for influenza A (RR: $0.80,95 \%$ CI: $0.68-0.93 ; P=0.004$ ) as shown in Fig. 5. Infants with low birth weight were also significantly reduced (RR: 0.74, 95\% CI: 0.59-0.92; $P=0.008$ ). Infants who were small for gestational age (RR: 0.95, 95\% CI: 0.83-1.09; $P=0.45$ ), stillbirth (RR: 0.63, 95\% CI: $0.38-1.03 ; P=0.07$ ), major birth defects (RR: $0.67,95 \%$ CI: $0.26-1.72 ; P=0.41$ ), admission to NICU (RR: 0.94, 


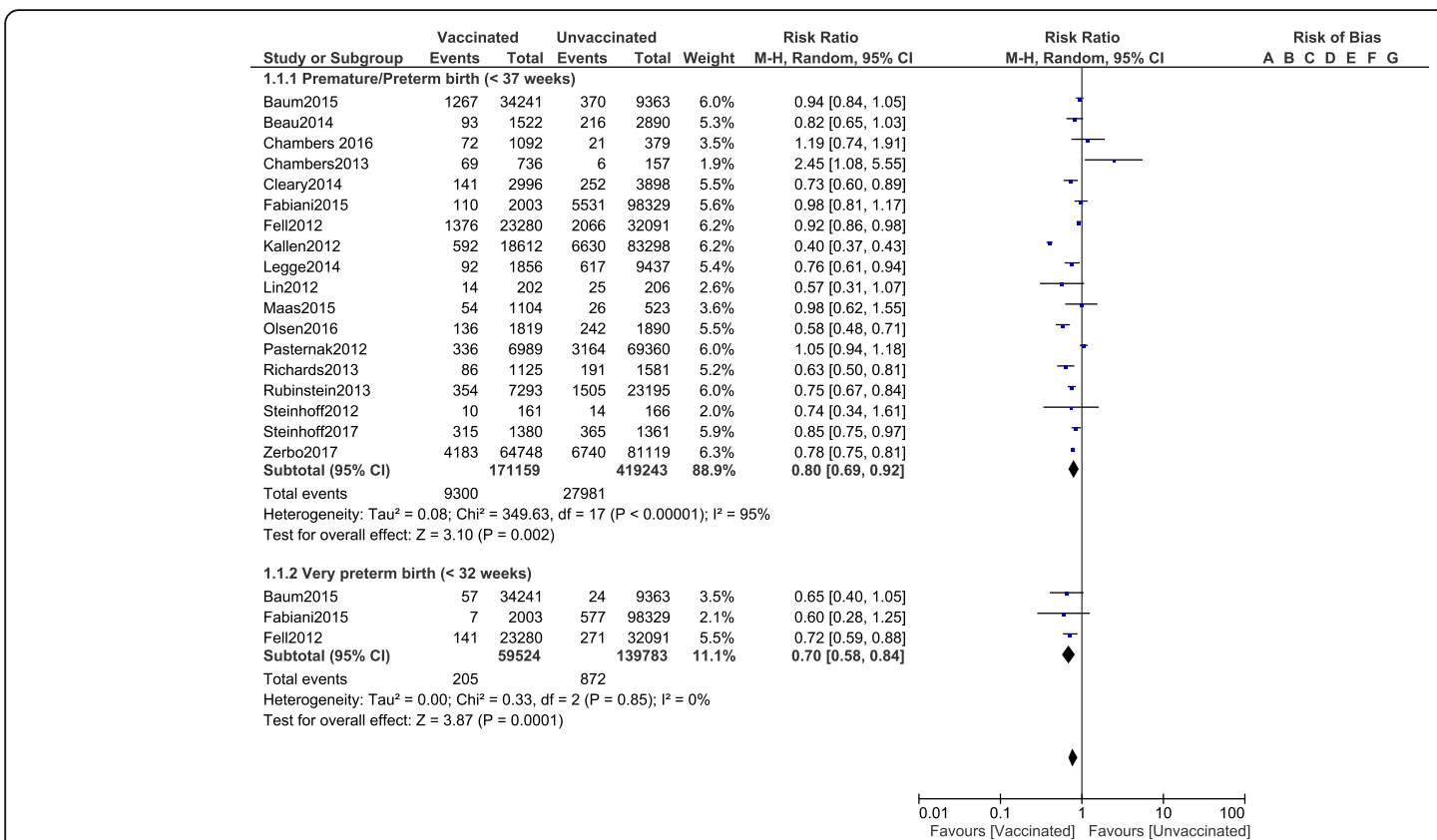

Fig. 2 Comparing the adverse fetal outcomes in pregnant women who were vaccinated versus who were not vaccinated for Influenza A (Part I)

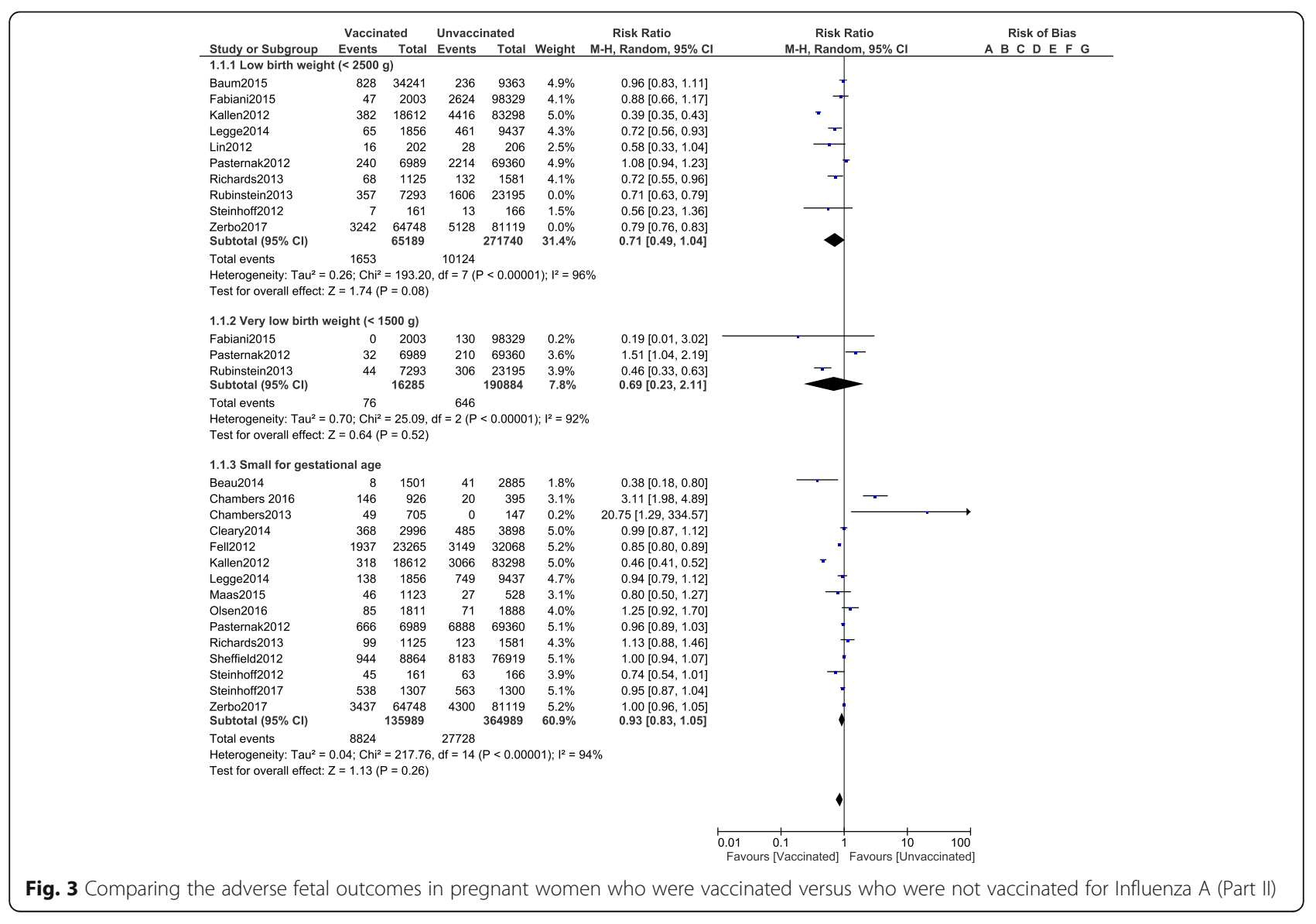




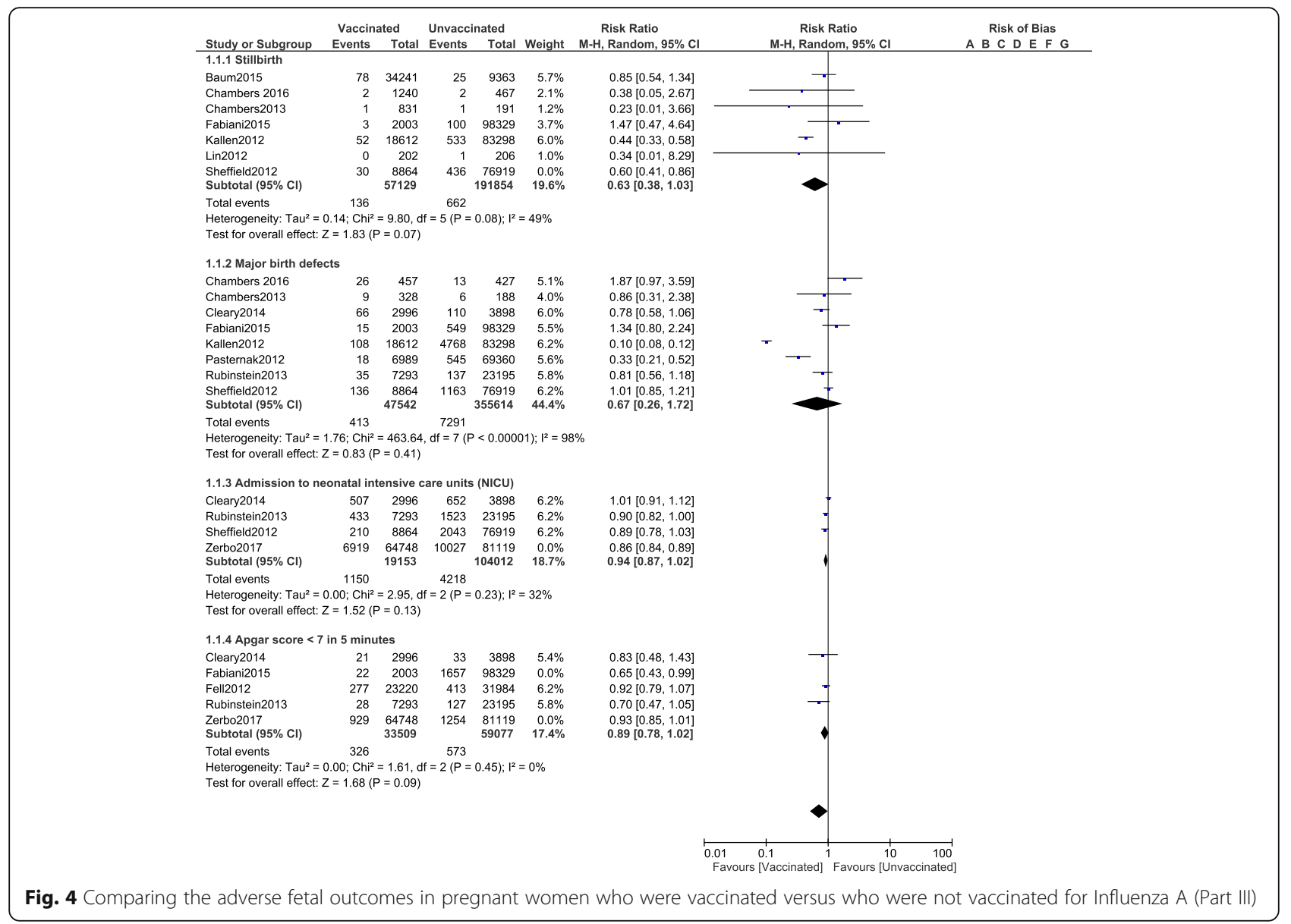

95\% CI: $0.87-1.02 ; P=0.13)$ and Apgar score $<7$ in 5 min (RR: $0.89,95 \%$ CI: $0.78-1.02 ; P=0.09$ ) were also not increased as shown in Fig. 5.

A summarized version of the result based on the safety of influenza A vaccination during pregnancy has been provided in Table 4.

Consistent results were obtained throughout based on a sensitivity analysis. Publication bias was represented by the funnel plot (Fig. 6).

\section{Discussion}

Our results were evidence to prove that influenza A vaccination in pregnancy was associated with a significantly lower risk of preterm birth and without increasing the risk of other adverse fetal outcomes including stillbirth, congenital malformations, poor Apgar score and admission to NICU showing a benefit of this vaccine in pregnancy.

Similarly, studies based in the United States of America and Europe demonstrated that maternal influenza vaccine is associated with a significantly high level of anti-influenza antibody thus showing a benefit for the mother as well as for the infant [36].
A recent systematic review and meta-analysis of observational studies found that influenza when manifested during pregnancy resulted in an increased risk of hospital admission compared to the nonpregnant controls [37]. This indicates that influenza vaccine during pregnancy is vital to reduce hospital admission and this particular vital piece of information should be communicated to the mass.

A conference report of the World Health Organization (WHO) technical consultation on the effect of maternal influenza and influenza vaccination on the development of the fetus: Montreal, Canada, September 30 - October 1, 2015 has been described [38].

In a large retrospective cohort including 74, 292 participants retrieved from seven Vaccine Safety Datalink sites which is a collaborative effort between the Immunization Safety Office of the centers for Disease Control and Prevention involving approximately $3 \%$ of the population of the United States, the authors demonstrated no association of influenza vaccine with increased adverse obstetrical events [39]. Another study also showed no associated risk of influenza vaccine on pregnancy outcomes [40]. 


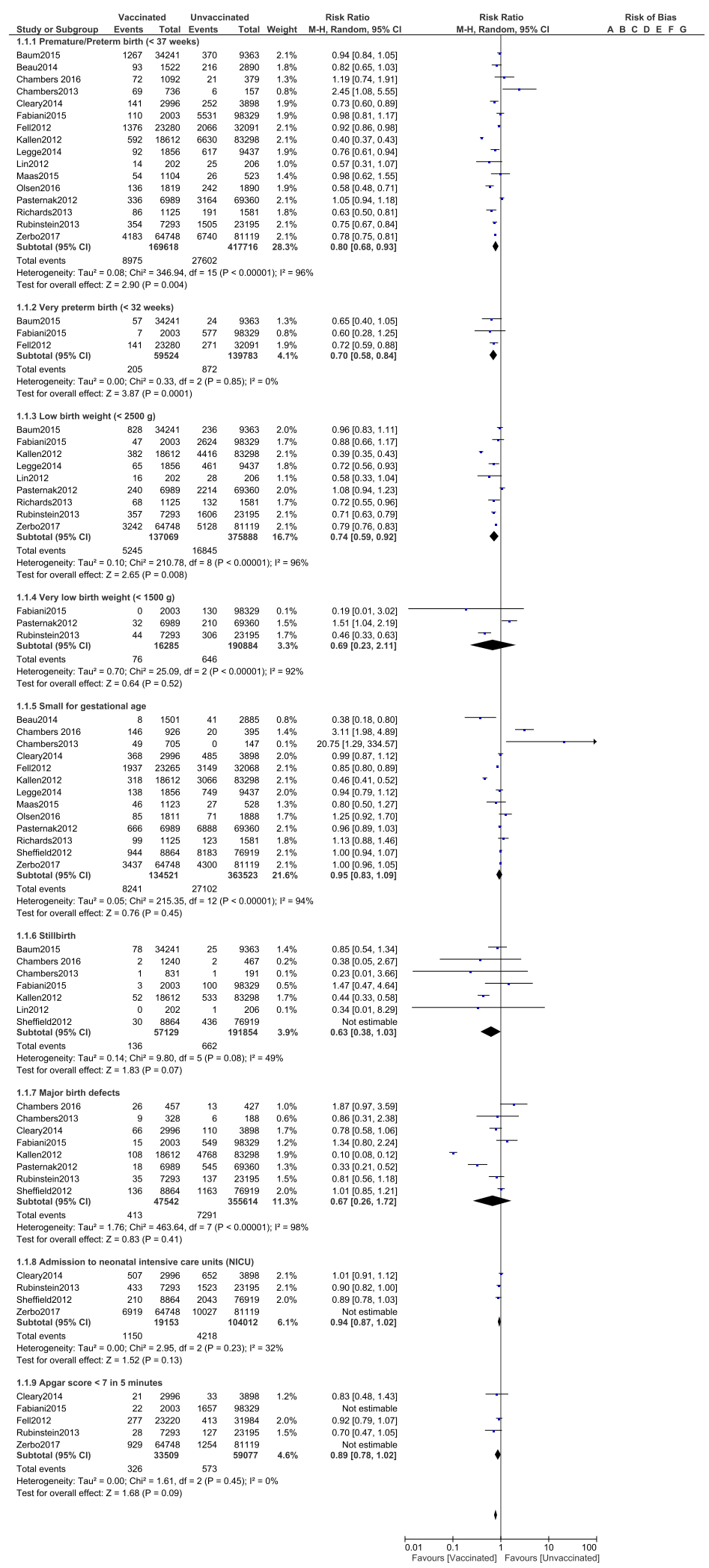

Fig. 5 Comparing the adverse fetal outcomes in pregnant women who were vaccinated versus who were not vaccinated for Influenza A using data only from observational studies 
Table 4 Results of the analysis

\begin{tabular}{lll}
\hline Endpoints which were assessed & RR with 95\% Cl & $\boldsymbol{P}$ values \\
\hline Premature/Preterm birth $(<\mathbf{3 7}$ weeks) & $0.80[0.69-0.92]$ & 0.002 \\
Very preterm birth $(<\mathbf{3 2}$ weeks) & $0.70[0.58-0.84]$ & 0.0001 \\
Low birth weight $(<\mathbf{2 5 0 0} \mathbf{~ g})$ & $0.71[0.49-1.04]$ & 0.08 \\
Very low birth weight $(<\mathbf{1 5 0 0} \mathbf{g})$ & $0.69[0.23-2.11]$ & 0.52 \\
Small for gestational age & $0.93[0.83-1.05]$ & 0.26 \\
Stillbirth & $0.63[0.38-1.03]$ & 0.07 \\
Major birth defects & $0.67[0.26-1.72]$ & 0.41 \\
Admission to NICU & $0.94[0.87-1.02]$ & 0.13 \\
Apgar score $<\mathbf{7}$ in $\mathbf{5}$ min & $0.89[0.78-1.02]$ & 0.09 \\
\hline
\end{tabular}

Abbreviations: RR Risk ratios, CI Confidence intervals, NICU Neonatal intensive care unit

Another cohort study from Denmark comprising of 54,585 pregnancies whereby 7062 women were vaccinated against influenza, no evidence of fetal death was observed with this vaccine given during pregnancy [41]. All those studies from different regions across the world are evidence to suggest the benefits of influenza A vaccine during pregnancy. This particular health communication should be spread across the concerned population of pregnant and non-pregnant women, as well as to their families. This public health issue is vital, for a healthier generation.
For a long time, people were affected by the sensitivity of pregnancy, and the particularity of vaccine and the complexity of influenza virus, faced many difficulties and challenges for a long time in scientific popularization, health education, risk communication and vaccine promotion of influenza A vaccination during pregnancy. Examples were: "does influenza A vaccination during pregnancy have side effects?," "Will health communication on influenza A vaccination during pregnancy be rejected by those conservative women?." In view of these issues, we must carefully and detailly operate our researches, and design communication strategies for influenza A vaccination in pregnancy.

Theory is the guide to practice, and this is of no exception for health communication based on influenza A vaccination in pregnancy. From the perspective of this issue, directly relevant theories on health communication were mainly presented as: Perception of Risks theory and Social Determinants of Health theory. Risk perception refers to individual's subjective cognition and judgment on any type of objective risks outside, yet risk perception on the health particularly refers to those cognitions and judgment of public on various factors, activities and common diseases that affect physical and mental health [42]. "Risk perception" plays an indispensable role in health and risk communication, which can help us investigate what concerns exist among the public

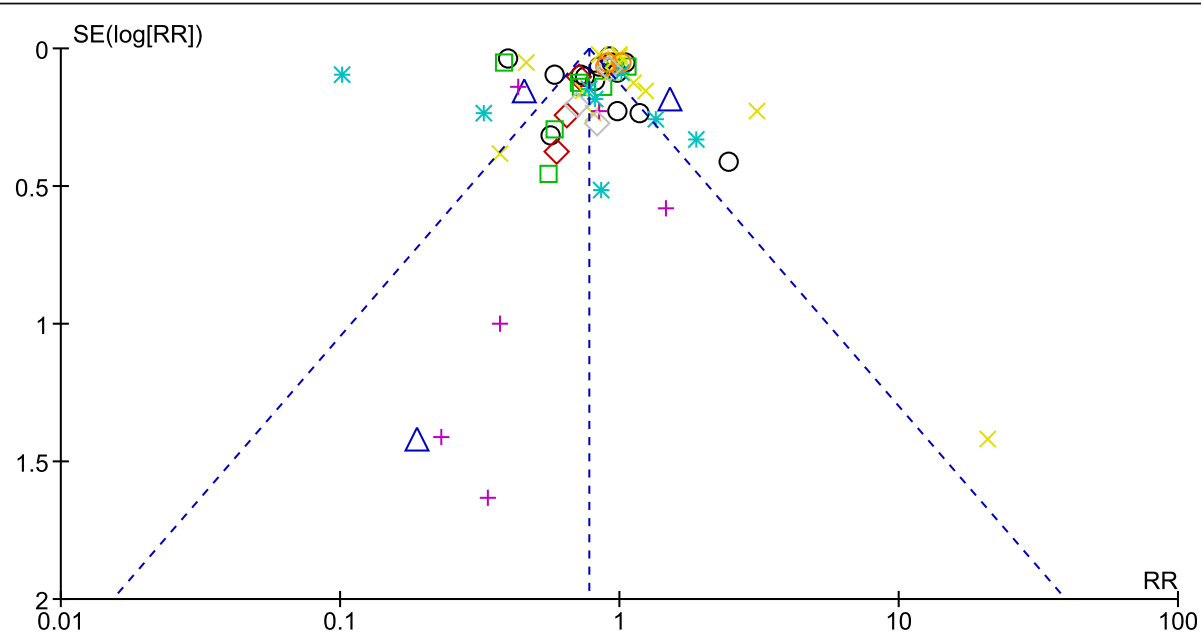

$$
\begin{aligned}
& \bigcirc \text { Pubgroups }- \text { Premature/Preterm birth }(<37 \text { weeks }) \\
& \checkmark \text { Very preterm birth }(<32 \text { weeks }) \\
& \square \text { Low birth weight }(<2500 \mathrm{~g}) \\
& \triangle \text { Very low birth weight }(<1500 \mathrm{~g}) \\
& \times \text { Small for gestational age } \\
& + \text { Stillbirth } \\
& * \text { Major birth defects } \\
& \text { Admission to neonatal intensive care units (NICU) } \\
& \text { Apgar score }<7 \text { in } 5 \text { minutes }
\end{aligned}
$$

Fig. 6 Funnel plot showing publication bias 
and understand people's related health behaviors, such as searching, selecting, and sharing health information. Because, a fact that cannot be ignored is that when people perceive potential health risks, they are often prone to falling into negative emotions, such as anxiety or even fear, and driven by the self-protection, they will actively seek information and solutions to change the current uneasy state. Wu Hairong and Shen Ying [43] studied and proved that community residents were allowed to understand the hazards of rabies and the risks of bites by dogs and cats, could improve their awareness of prevention, attitude and behavior of rabies (KAP); Brewer NT [44] also demonstrated that there exists a positive correlation between risk perception and health behaviors, that is, individuals 'awareness of health risks can increase their concerns about health risks and their compliance with actions. As to this phenomenon, the Protection Motivation Theory (PMT) also gives a similar explanation. It is in the above sense that we can say without hesitation: Risk perception constitutes an effective predictor of decision-making and intervention for health. In addition, the Health Social Factor Theory $(\mathrm{SDOH})$ emphasizes that people's health risks and quality of life are affected by people's living resources, educational opportunities, medical and health services, community environment, and social norms, to some extent. WHO [45] states that if we want to improve people's health worldwide, we must do three basic tasks: educational intervention, social protection intervention and urban development intervention. Yet, education intervention is the so-called direct health communication intervention.

Based on the above two theories, we focus on advocating the following skills and methods for the communication of influenza A vaccination during pregnancy, to accomplish the special social issue into a larger spread in pregnant women and society. In general, for the sake of reducing doubts and eliminating traditional misunderstanding from the pregnant women and the public, we must adhere to the principle of "active behavior, scientific guidance"-based on facts and science, to guide them to correctly understand and judge the safety of vaccines. Specifically, the health communication and education on this topic can be strengthened and improved from such aspects, as follows:

(1) To Enter correct and scientific health information for preventing fatalism and nihilism in heath communication. Fatalism and nihilism are often synonymous with meaninglessness, hopelessness, and inaction. Related researches in the field of health communication, also shows that thus beliefs constitute an invisible wall and a major barrier for our carrying out medical care, which affects disease prevention, early detection and treatment $[46,47]$. Influenced by fatalism, people believe that health problems are not under control of human beings and are "destined" to be unsolvable. Fatalism also exists on the issue of influenza A vaccination in pregnancy. Many women, for example, still believe that "there is no way to prevent the occurrence and spread of influenza virus", "there is no way to reduce the possibility of infection by influenza virus", "even if influenza A vaccination in pregnancy is safe, it will not escape from its side effects." According to fatalism, it makes no sense to operate health communication and educational intervention, which is diametrically opposed to risk perception theory. The latter insists that public, once realizing the health risks, will tend to actively seek information to avoid risks. Also, Practice and a large number of studies have confirmed that a significant positive correlation exist between people's health communication/interventions for risks and their behaviors for health. Therefore, we must make a difference in the safety of influenza A vaccination during pregnancy, through filtering and visual presentation to input correct and scientific health information towards pregnant women and the public, and prevent their negative attitudes to health behaviors. In addition to considering those actual needs in society and adopting those communication methods popular with the public, relevant news production and its spread must be continuous for the safety of influenza $\mathrm{A}$ vaccination during pregnancy, rather than in an intermittent state. Only by a long-term guidance can people's traditional perception for the event be effectively changed.

(2) Public institutions for health education should make full use of authoritative media, especially social media, to promote the penetration and reach of health information. In the era of mass communication, the media, like traditional schools and churches, undertake important responsibilities in social enlightenment and cultural education. Especially with the advent of social media and mediated society, the way people understand the world and the interactions between them have gradually become socialized and stratified. Social media, due to its efficient interaction, diverse structure and advantages of crossing spaces, has turned into the mainstream media in our society [48]. This communication phenomenon also exists in the realm of health communication. An American survey in 2017 showed that 74\% of Internet users surfed on social media; $80 \%$ of them searched for health information; $30 \%$ of adults used social media to share the health information with other patients [49]. Given the media and social platforms have been an important channel for health communication, in which people search for, write, evaluate and share health information, detailed and authoritative facts/truths about the safety of influenza vaccines, should be provided to pregnant women through the media and especially social networks by public medical institutions for health and 
popular science, and a deeply interaction with the audience, be operated through new media's flat and multipolar characteristics to answer questions, enhance mutual trust/ the penetration of heath information, and reduce false information. Furthermore, about the influenza A vaccination during pregnancy, relevant organizations can also use social media to create topic groups (an effective way to gather target audiences), and bring humanistic care to the communication, which contributes to a comprehensive interaction between doctors and audience, and comforts pregnant women with the support and encouragement from those who have been vaccinated.

(3) To cultivate professional "opinion leaders" for health communication and value realistic community communication, $\mathrm{SDOH}$ theory believes that individual's cognitions and attentions for health risks are also affected by social factors. Hence, a type of reasonable health communication and interventions must be implemented, for the improvement of public health. Obviously, the communication and persuasion for influenza A vaccination during pregnancy, an indispensable part of public health, are not only vitally interrelated with the intrinsic content and quality of information, but depend on other factors, such as communicators' credibility, and the community environment/culture in which the audience live. Especially in those cultural systems that value traditions and collectivism, SDOH theory has much more considerable vitality in explaining public KAP model for health information. In light of this, through cultivating professional opinion leaders for health communication and interventions may we be able to make it widely known towards women and society that influenza A vaccination is securely-guaranteed. Genuinely speaking, slightly more materials, money and time may be consumed in "fostering opinion leaders" (such as wellknown scholars and scientist in the medical field), and "drawing support from traditional community communication" (such as doctor's visits and on-site education in public occasions), compared with the communication and intervention by social media. However, these methods above all will absolutely enhance mutual trust and effective communication for health information in a way that more lives up to people's psychology.

In this study, the authors focused on the effect of influenza A/H1N1pdm09 vaccine on fetal outcomes, although a quadrivalent influenza vaccine has also usually been used in the general influenza season. To support monovalent vaccination as in this current study, another research article [50] based on the immunogenicity and efficacy of the monovalent, trivalent and quadrivalent intranasal live attenuated influenza vaccines containing different pdmH1N1 strains showed viral titres in the nose to have significantly been reduced in animals who were vaccinated with monovalent vaccines compared to those who were vaccinated with trivalent and quadrivalent vaccines of both the strains and it was only the monovalent vaccines containing the $\mathrm{A} / \mathrm{Cal}$ strain that significantly reduced the viral load. In conclusion, the authors also stated that the monovalent vaccines appeared to be superior and provided complete protection from infections during a pandemic. Monovalent vaccines has other advantages. A meta-analysis even showed that pregnant women who received monovalent vaccines for H1N1 were less likely to deliver low birth weight babies [51]. Another published article showing variable influenza vaccine effectiveness by subtype also showed monovalent vaccine to be more effective [52]. The study showed that vaccine efficiency against influenza type B and H1N1pdm09 was greater than 50\% among all age group. Even though this current analysis was based on monovalent influenza vaccine, a recent randomized, observer-blind trial based on the immunogenicity and safety of the quadrivalent inactivated influenza vaccine in pregnant women showed the latter to be equally safe [53]. No vaccine related adverse pregnancy outcomes or congenital malformations were reported. However, since it was the first study to evaluate the efficacy of quadrivalent influenza vaccine in pregnant women, with a limited number of participants and since the study only included 2nd and 3rd trimester pregnant women, it would be recommended to better await further studies to confirm the safety of the quadrivalent influenza vaccine in pregnant women.

At last, one of the limitations of this meta-analysis was a high level of heterogeneity when assessing several subgroups. However, it should be noted that data from several studies including randomized trials, cohort studies and cross sectional studies were included and the introduction of bias was obvious as stated in a vaccinerelated article [54]. Also, even if heterogeneity was very high in most of the cases, no graphical representation [55] was included to show which articles were more influential in heterogeneity because we already carried out a leave one out analysis. In addition, the time period when the vaccine was given was not taken into consideration whether it was given during the first, second or third trimester believing that it was at least given during pregnancy. Furthermore, the presence of covariates, selection bias and other types of bias might have affected the results. Also, several other baseline features were not reported in the original studies, and hence, we were unable to include some more details about these baseline characteristics of the pregnant women in this analysis.

\section{Conclusion}

Influenza vaccine is completely safe in pregnancy. It significantly lowers premature birth and is not associated 
with any serious adverse neonatal outcome. Hence, this important piece of information should be communicated and conveyed to all pregnant women, for a safer and healthier pregnancy. At last, this public health issue should further be addressed to the population through media and other communication means in order to improve the rate of influenza $A$ vaccines in pregnant women for a healthier and more productive population.

\section{Abbreviations}

SHDPP: Stanford Heart Disease Prevention Program; CDC: Centers for Disease Control and Prevention; H1N1: Influenza A; SAGE: Strategic Advisory Group of Experts on Immunization; RR: Risk ratio; Cl: Confidence interval; WHO: World Health Organization

\section{Acknowledgements}

Not applicable.

\section{Authors' contributions}

The authors QCL, TYZ, PKB and CC were responsible for the conception and design, acquisition of data, analysis and interpretation of data, drafting the initial manuscript and revising it critically for important intellectual content. Authors QCL and TYZ wrote this manuscript. All the authors agreed to and approved the manuscript as it is.

\section{Funding}

There was no external source of funding for this research.

\section{Availability of data and materials}

All data and materials used in this research are freely available in electronic databases (MEDLINE, EMBASE, Cochrane database, Google scholar).

References have been provided.

\section{Declarations}

Ethics approval and consent to participate

Ethical approval was not applicable for this systematic review and metaanalysis.

\section{Consent for publication}

Not applicable.

\section{Competing interests}

The authors declare that they have no competing interests.

\section{Author details \\ ${ }^{1}$ Department of Obstetrics and Gynaecology, National Hospital of Guangxi Zhuang Autonomous Region, Affiliated to Guangxi Medical University, Nanning, Guangxi 530000, People's Republic of China. ${ }^{2}$ Department of Communication, School of Journalism and New Media, Xi'An JiaoTong University, Xi'An, Shanxi 710000, People's Republic of China. ${ }^{3}$ Department of Internal Medicine, Flacq Hospital, Central Flacq, Mauritius. ${ }^{4}$ Department of Broadcasting and Television, School of Journalism and Information Communication, Huazhong University of Science and Technology, Wuhan 430000, People's Republic of China.}

\section{Received: 18 April 2020 Accepted: 30 March 2021}

Published online: 09 April 2021

\section{References}

1. Rogers EM. The field of health communication today: an up-to-date report. J Health Commun. 1996;1(1):15-23.

2. Roper WL. Health communication takes on new dimensions at CDC. Public Health Rep. 1993;108(2):179-83.

3. Wang J, Sun D, Abudusaimaiti X, Vermund SH, Li D, Hu Y. Low awareness of influenza vaccination among pregnant women and their obstetricians: a population-based survey in Beijing, China. Hum Vaccin Immunother. 2019;1: $1-7$.
4. Sakala IG, Honda-Okubo Y, Fung J, Petrovsky N. Influenza immunization during pregnancy: benefits for mother and infant. Hum Vaccin Immunother. 2016;12(12):3065-71. https://doi.org/10.1080/21645515.2016.1215392.

5. Ditsungnoen D, Greenbaum A, Praphasiri P, Dawood FS, Thompson MG, Yoocharoen $\mathrm{P}$, et al. Knowledge, attitudes and beliefs related to seasonal influenza vaccine among pregnant women in Thailand. Vaccine. 2016; 34(18):2141-6. https://doi.org/10.1016/j.vaccine.2016.01.056.

6. McLean HQ, Fiebelkorn AP, Temte JL, Wallace GS, Centers for Disease Control and Prevention. Prevention of measles, rubella, congenital rubella syndrome, and mumps, 2013: summary recommendations of the Advisory Committee on Immunization Practices (ACIP). MMWR Recomm Rep. 2013; 62(RR-04):1-34.

7. Meijer WJ, van Noortwijk AG, Bruinse HW, Wensing AM. Influenza virus infection in pregnancy: a review. Acta Obstet Gynecol Scand. 2015;94(8): 797-819. https://doi.org/10.1111/aogs.12680.

8. Littauer EQ, Esser ES, Antao OQ, Vassilieva EV, Compans RW, Skountzou I. H1N1 influenza virus infection results in adverse pregnancy outcomes by disrupting tissue-specific hormonal regulation. PLoS Pathog. 2017;13(11): e1006757. https://doi.org/10.1371/journal.ppat.1006757.

9. ACOG Committee Opinion No. 732: Influenza Vaccination During Pregnancy. Obstet Gynecol. 2018;131(4):e109-14. https://doi.org/10.1097/A OG.0000000000002588.

10. PHE. Chapter 19: Influenza. In: The Green Book. PHE. 2018. https://assets. publishing.service.gov.uk/government/uploads/system/uploads/attachment_ data/file/733840/Influenza_green_book_chapter19.pdf. Accessed 12 Jan 2018.

11. Wilson R, Paterson $P$, Larson HJ. Strategies to improve maternal vaccination acceptance. BMC Public Health. 2019;19(1):342. https://doi.org/10.1186/s12 889-019-6655-y.

12. PHE. Seasonal influenza vaccine uptake in GP patients in England: winter season 2016 to 2017. In: Health protection report: PHE; 2017. https://assets. publishing.service.gov.uk/government/uploads/system/uploads/attachment_ data/file/613452/Seasonal_influenza_vaccine_uptake_in_GP_patients_ winter_season_2016_to_2017.pdf.

13. Stang A. Critical evaluation of the Newcastle-Ottawa scale for the assessment of the quality of nonrandomized studies in meta-analyses. Eur J Epidemiol. 2010;25(9):603-5. https://doi.org/10.1007/s10654-010-9491-z.

14. Higgins JP, et al. Assessing risk of bias in included studies, in Cochrane handbook for systematic reviews of interventions: Wiley; 2008. p. 187-241.

15. Baum U, Leino T, Gissler M, Kilpi T, Jokinen J. Perinatal survival and health after maternal influenza a(H1N1)pdm09 vaccination: a cohort studyof pregnancies stratified by trimester of vaccination. Vaccine. 2015;33(38):48507. https://doi.org/10.1016/j.vaccine.2015.07.061.

16. Beau AB, Hurault-Delarue $C$, Vidal $S$, Guitard C, Vayssière C, Petiot $D$, et al. Pandemic a/H1N1 influenza vaccination during pregnancy: a comparative study using the EFEMERIS database. Vaccine. 2014;32(11):1254-8. https://doi. org/10.1016/j.vaccine.2014.01.021.

17. Chambers CD, Johnson D, Xu R, Luo Y, Louik C, Mitchell AA, et al. Risks and safety of pandemic H1N1 influenza vaccine in pregnancy: birth defects, spontaneous abortion, preterm delivery, and small for gestational age infants. Vaccine. 2013;31(44):5026-32. https://doi.org/10.1016/j.vaccine.2013.08.097.

18. Chambers CD, Johnson DL, Xu R, Luo YJ, Louik C, Mitchell AA, et al. Safety of the 2010-11, 2011-12, 2012-13, and 2013-14 seasonal influenza vaccines in pregnancy: birth defects, spontaneous abortion, preterm delivery, and small for gestational age infants, a study from the cohort arm of VAMPSS. Vaccine. 2016;34(37):4443-9. https://doi.org/10.1016/j.vaccine.2016.06.054.

19. Cleary BJ, Rice Ú, Eogan M, Metwally N, McAuliffe F. 2009 A/H1N1 influenza vaccination in pregnancy: uptake and pregnancy outcomes - a historical cohort study. Eur J Obstet Gynecol Reprod Biol. 2014;178:163-8. https://doi. org/10.1016/j.ejogrb.2014.04.015.

20. Fabiani M, Bella A, Rota MC, Clagnan E, Gallo T, D'Amato M, et al. A/H1N1 pandemic influenza vaccination: a retrospective evaluation of adverse maternal, fetal and neonatal outcomes in a cohort of pregnant women in Italy. Vaccine. 2015;33(19):2240-7. https://doi.org/10.1016/j.vaccine.2015.03.041.

21. Fell DB, Sprague AE, Liu N, Yasseen AS 3rd, Wen SW, Smith G, et al. H1N1 influenza vaccination during pregnancy and fetal and neonatal outcomes. Am J Public Health. 2012;102(6):e33-40. https://doi.org/10.2105/AJPH.2011.3 00606.

22. Källén B, Olausson PO. Vaccination against H1N1 influenza with Pandemrix $\left.{ }^{(}\right)$during pregnancy and delivery outcome: a Swedish register study. BJOG. 2012;119(13):1583-90. https://doi.org/10.1111/j.1471-0528.2012.03470.x. 
23. Legge A, Dodds L, MacDonald NE, Scott J, McNeil S. Rates and determinants of seasonal influenza vaccination in pregnancy and association with neonatal outcomes. CMAJ. 2014;186(4):E157-64. https://doi.org/10.1503/cma j.130499.

24. Lin TH, Lin SY, Lin CH, Lin Rl, Lin HC, Chiu TH, et al. AdimFlu-S( $\left(^{\circledR}\right)$ influenza a (H1N1) vaccine during pregnancy: the Taiwanese Pharmacovigilance survey. Vaccine. 2012;30(16):2671-5. https://doi.org/10.1016/j.vaccine.2012.02.008.

25. van der Maas N, Dijs-Elsinga J, Kemmeren J, van Lier A, Knol M, de Melker H. Safety of vaccination against influenza a (H1N1) during pregnancy in the Netherlands: results on pregnancy outcomes and infant's health: crosssectional linkage study. BJOG. 2016;123(5):709-17. https://doi.org/10.1111/14 71-0528.13329.

26. Olsen SJ, Mirza SA, Vonglokham P, Khanthamaly V, Chitry B, Pholsena V, et al. The effect of influenza vaccination on birth outcomes in a cohort of pregnant women in LaoPDR, 2014-2015. Clin Infect Dis. 2016;63(4):487-94. https://doi.org/10.1093/cid/ciw290.

27. Pasternak B, Svanström H, Mølgaard-Nielsen D, Krause TG, Emborg HD Melbye $\mathrm{M}$, et al. Risk of adverse fetal outcomes following administration of a pandemic influenza a (H1N1) vaccine during pregnancy. JAMA. 2012; 308(2):165-74. https://doi.org/10.1001/jama.2012.6131.

28. Richards JL, Hansen C, Bredfeldt C, Bednarczyk RA, Steinhoff MC, AdjayeGbewonyo D, et al. Neonatal outcomes after antenatal influenza immunization during the 2009 H1N1 influenza pandemic: impact on preterm birth, birth weight, and small for gestational age birth. Clin Infect Dis. 2013;56(9):1216-22. https://doi.org/10.1093/cid/cit045

29. Rubinstein F, Micone P, Bonotti A, Wainer V, Schwarcz A, Augustovski F, et al. Influenza A/H1N1 MF59 adjuvanted vaccine in pregnant women and adverse perinatal outcomes: multicentre study. BMJ. 2013;346:f393.

30. Sheffield JS, Greer LG, Rogers VL, Roberts SW, Lytle H, McIntire DD, et al. Effect of influenza vaccination in the first trimester of pregnancy. Obstet Gynecol. 2012;120(3):532-7. https://doi.org/10.1097/AOG.0b013e318263a278.

31. Steinhoff MC, Omer SB, Roy E, El Arifeen S, Raqib R, Dodd C, et al. Neonatal outcomes after influenza immunization during pregnancy: a randomized controlled trial. CMAJ. 2012;184(6):645-53. https://doi.org/10.1503/cmaj.11 0754 .

32. Steinhoff MC, Katz J, Englund JA, Khatry SK, Shrestha L, Kuypers J, et al. Yearround influenza immunisation during pregnancy in Nepal: a phase 4, randomised, placebo-controlled trial. Lancet Infect Dis. 2017;17(9):981-9. https://doi.org/10.1016/S1473-3099(17)30252-9.

33. Zerbo O, Modaressi S, Chan B, Goddard K, Lewis N, Bok K, et al. No association between influenza vaccination during pregnancy and adverse birth outcomes. Vaccine. 2017;35(24):3186-90. https://doi.org/10.1016/j.va ccine.2017.04.074.

34. Copas JB, Shi JQ. A sensitivity analysis for publication Bias in systematic reviews. Stat Methods Med Res. 2001;10(4):251-65. https://doi.org/10.1177/ 096228020101000402

35. Liberati A, Altman DG, Tetzlaff J, Mulrow C, Gøtzsche PC, loannidis JP, et al. The PRISMA statement for reporting systematic reviews and meta-analyses of studies that evaluate healthcare interventions: explanation and elaboration. BMJ. 2009;339:b2700. https://doi.org/10.1136/bmj.b2700.

36. Marshall H, McMillan M, Andrews RM, Macartney K, Edwards K. Vaccines in pregnancy: the dual benefit for pregnant women and infants. Hum Vaccin Immunother. 2016;12(4):848-56. https://doi.org/10.1080/21645515.2015.112 7485.

37. Mertz D, Geraci J, Winkup J, Gessner BD, Ortiz JR, Loeb M. Pregnancy as a risk factor for severe outcomes from influenza virus infection: a systematic review and meta-analysis of observational studies. Vaccine. 2017;35(4):521-8. https://doi.org/10.1016/j.vaccine.2016.12.012

38. Fell DB, Bhutta ZA, Hutcheon JA, Karron RA, Knight M, Kramer MS, et al. Report of the WHO technical consultation on the effect of maternal influenza and influenza vaccination on the developing fetus: Montreal, Canada, September 30-October 1, 2015. Vaccine. 2017:35(18):2279-87. https://doi.org/10.1016/j.vaccine.2017.03.056

39. Nordin JD, Kharbanda EO, Vazquez-Benitez G, Lipkind H, Lee GM, Naleway AL. Monovalent H1N1 influenza vaccine safety in pregnant women, risks for acute adverse events. Vaccine. 2014;32(39):4985-92. https://doi.org/10.1016/ j.vaccine.2014.07.017

40. Kharbanda EO, Vazquez-Benitez G, Lipkind H, Naleway A, Lee G, Nordin JD, et al. Inactivated influenza vaccine during pregnancy and risks for adverse obstetric events. Obstet Gynecol. 2013;122(3):659-67. https://doi.org/10.1 097/AOG.0b013e3182a1118a.
41. Pasternak B, Svanström H, Mølgaard-Nielsen D, Krause TG, Emborg HD, Melbye M, et al. Vaccination against pandemic a/H1N1 2009 influenza in pregnancy and risk of fetal death: cohortstudy in Denmark. BMJ. 2012;344: e2794. https://doi.org/10.1136/bmj.e2794

42. Liu J. Understanding, communication and control: Public's risk perception. Beijing: Science Press; 2011.

43. Shen $Y$. A research on the effect of community health communication intervention on rabies [D]: Guangxi University; 2019.

44. Brewer N T, Weinstein N D, (2004). Cuite C L, et al. Risk perceptions and their relation to risk behavior. Ann Behav Med, 27 (2):125-130, DOl: https:// doi.org/10.1207/s15324796abm2702 7 .

45. WHO. The Economics of Social Determinants of Health and Health Inequalties:A Resource Book. Geneva: WHO Press; 2013.

46. Freeman HP. Cancer in the socioeconomically disadvantaged. Ca A Cancer J Clin. 1998;39(5):266-88.

47. Powe BD, Johnson A. Fatalism as a Barrier to Cancer Screening Among African- Americans: Philosophical Perspectives. J Relig Health. 1995;34(2): $119-25$.

48. Yu G, Li B. Management for Public Opinion in the era of social networks. Nanjing: Jiangsu People's Publishing House; 2015.

49. SMA. Social Media \& Health Care by the Numbers [EB/OL]. https://sma.org/ social-media-healthcare-by-the-numbers/, 2020.

50. Yeolekar LR, Ganguly M, Tyagi P, et al. Immunogenicity and efficacy of the monovalent, trivalent and quadrivalent intranasal live attenuated influenza vaccines containing different pdmH1N1 strains. Vaccine. 2018;36(46):694452.

51. Nunes MC, Aqil AR, Omer SB, Madhi SA. The effects of influenza vaccination during pregnancy on birth outcomes: a systematic review and metaanalysis. Am J Perinatol. 2016;33(11):1104-14.

52. Belongia EA, Simpson MD, King JP, et al. Variable influenza vaccine effectiveness by subtype: a systematic review and meta-analysis of testnegative design studies. Lancet Infect Dis. 2016;16(8):942-51.

53. Vesikari T, Virta M, Heinonen S, Eymin C, Lavis N, Chabanon AL, et al. Immunogenicity and safety of a quadrivalent inactivated influenza vaccine in pregnant women: a randomized, observer-blind trial. Hum Vaccin Immunother. 2020;16(3):623-9. https://doi.org/10.1080/21645515.2019.16672 02.

54. Donzelli A. Influenza Vaccinations for All Pregnant Women? Better Evidence Is Needed. Int J Environ Res Public Health. 2018;15(9).

55. Baujat B, Mahé C, Pignon JP, Hill C. A graphical method for exploring heterogeneity in meta-analyses: application to a meta-analysis of 65 trials. Stat Med. 2002;21(18):2641-52. https://doi.org/10.1002/sim.1221.

\section{Publisher's Note}

Springer Nature remains neutral with regard to jurisdictional claims in published maps and institutional affiliations.
Ready to submit your research? Choose BMC and benefit from:
- fast, convenient online submission
- thorough peer review by experienced researchers in your field
- rapid publication on acceptance
- support for research data, including large and complex data types
- gold Open Access which fosters wider collaboration and increased citations
- maximum visibility for your research: over $100 \mathrm{M}$ website views per year
At BMC, research is always in progress.
Learn more biomedcentral.com/submission 